\title{
THE CHANGED STATUS OF SOIME INSECT PESTS IN PUERTO RICO
}

\author{
By George N. Wolcott, Entomologist, \\ Insular Experiment Station, Río Piedras, Puerto Rico.
}

A few of the insect pests of economic crops in Puerto Rico show little or no change in their status over a period extending as far back as any entomological observations are recorded. For instance, the purple scale of citrus trees, Lepidosaphes beckii Newman, has been and still is THE scale for which growers spray or maintain windbreaks, obtaining commercial control thereby, but never reducing its numbers below a certain minimum from which it will promptly recover under favorable conditions. The mole-cricket, or changa, Scapteriscus vicinus Scudder, is generally quite as much of a pest now as it has ever been in the past, the decrease in its numbers reported by some farmers due to toads being more than balanced by increased damage reported in other districts, due either to a more intensive type of agriculture or to an actual increase in its numbers. In the regions where the use of the standard Paris green-flour mixture for poisoning the changa is still in common use, it probably is now less abundant than formerly, but where farmers have reverted to merely protecting young plants against its attack by wrapping them in mamey leaves when transplanted, it is subject to no control except natural factors. To be sure, it is eaten by the imported giant toad, Bufo marinus, but apparently only in limited areas has a noticeable reduction in its numbers resulted.

Of the pests which have appeared here in recent years, the latest arrival is the cottony cushion scale, Icerya purchasi Maskell. A detailed account of this insect is given elsewhere in this number of the Journal (1), noting its peak of abundance in the late spring of 1932, and the role of parasites, predators, entomogenous fungi and hurricanes in its control. Coccus viridis Green, the soft green scale of citrus and coffee, was first noted in 1925, and became noticeably destructive in the coffee groves denuded of shade by the hurricane of San Felipe in 1928. Its present status largely depends on local humidity, for its numbers are greatly reduced by at least two kinds of entomogenous fungi attacking it, which thrive during wet weather. Thus it is rarely injurious on large citrus trees, or in coffee groves well protected by shade, but during dry weather may be seriously 
injurious on young citrus trees. In 1921, two pests appeared almost simultaneously in Puerto Rico, the pink bollworm of cotton, Pcctinophora gossypiella Saunders, and the corm borer of plantains and bananas, Cosmopolites sordidus Germar, both of which now occur practically everywhere that appropriate host plants are present. The latter pest apparently has no natural enemies, and comparatively few growers practise, or even know, the practical methods of control by which its numbers may be reduced to a minimum. The rapiclity with which it has spread, and the abundance in which it is now present, does not inclicate, however, that other insects with similar habits will be similarly successful. The sweet potato weevil, Cylas formicarius $\mathrm{F}$., altho a most serious pest in the poor, hilly lands of the interior, is of comparatively little importance on the richer loams or the sandy lands of the coast, where the host grows to much better advantage, matures more rapidly, and is further protected from attack by the absence of cracks in the soil thru which the insect can reach the tubers. Even less successful in extending its range is another weevil of sweet potatoes, the scarabee, Euscepes batatae Waterhouse, which is still confined to limited areas where the first records of its presence in Puerto Rico were made. Its limited distribution is paralleled in the case of the papaya fruit fly, Toxotrypana curvicanda Gerstaecker, which is comparatively rare even in the restricted region where it is present.

For the 29-year period, 1899 to 1928, no generally and seriously destructive hurricanes have happened to strike Puerto Rico. One consequence of this lengthy immunity from hurricanes was that the coffee shade tree ant, the "hormiguilla", Myrmelachisto ambigua ramulorum Wheeler, became constantly more abundant, for old infested shade trees in the coffee groves became so large that they could not be removed without injury to the coffee trees underneath. The hurricane of San Felipe brought down these old guaba and guamá trees, thus immediately eliminating the great bulk of the hormiguilla population of the grove. Only gradually, over a period of several years, as the freshly planted shade trees again attain considerable size, will the numbers of the hormiguilla again begin to increase.

The hurricane incidentally increased the number of the more common cotton insect pests in the few years immediately following, for the impoverished coffee growers in many cases attempted to grow cotton for a cash crop. Waves of infestation by the leaf caterpillar, Alabama argillacea Hübner, swept over these plantings, and infestations of the pink bollworm were built up, culminating in almost 
THE CHANGED STATUS OF SOME INSECT PESTS IN PUERTO RICO 267

total infestation of the end of the crop for 1931-32. From this high peak, cotton insects rapidly receded, due to the discouraged coffee planters abandoning the crop, and even cotton farmers ceasing to plant on account of low prices and the withdrawal of the sole buyer. The hurricane of San Ciprián in the fall of 1932 destroyed the fruiting portions of the maga trees, thus eliminating the only important alternate host of the pink bollworm along the north coast. Where volunteer cotton plants still exist, the pink bollworm continues to persist, but in the main cotton region, around Isabela, where volunteer cotton plants had been eliminated years ago, the destruction of the fruiting portions of the maga trees and the absence of commercial cotton fields have, temporarily at least, entirely eliminated this pest from the region.

Replacing the old standard varieties of sugar-cane grown in Puerto Rico with BH (10)12 and SC 12(4) has considerably increased tonnage and sugar content, but it has also affected the common caterpillar, Diatraea saccharalis F., which bores in the stalks, most advantageously to the insect. The new eanes are larger: and softer and sweeter than the old, and they appear to furnish a more desirable environment for the insect. Thus the numbers of this; the most scrious pest of sugar-cane, have been on the increase, despite the fact that the non-burning of trash has been ever more widely adopted. Favoring its parasites by non-burning of trash can not begin to neutralize the effect of a more favorable environment furnished by the new varieties of cane. Thus, altho the net result of the change of varieties has been to increase production, this is despite the greater losses at present being caused by Diatraea. The stalk borer is not the only insect affected by the change in varieties. What was previously only a minor pest of sugar cane, the yellow aphid, Sipha flava Forbes, has also thereby been provided with a greatly superior host, from its standpoint. Because of some undetermined peculiarity of Uba and the Java canes, it often becomes enormously abuindant on these varieties, and such mass infestations spread to adjoining fields of B H (10) 12 and S C 12 (4), causing much greater and more extensive losses from this pest than were ever known on the standard varieties.

The major and most obvious change which has occurred recently is in the status of white grubs, the numbers of which have decreased so greatly that only rarely and sporadically do they. cause serious damage. Fifteen or twenty years ago the damage caused by white grubs had attained its maximum, and at that time they were the 
most serious pests of practically every crop grown on the island, such damage being most severe in the irrigated cane lands of the south coast. It was a common occurrence to have nearly mature cane so completely denuded of roots that the stalks could be pulled up with ease, or, in extreme cases, they would fall to the ground at a touch. White grubs were distinctly the main entomological problem in Puerto Rico, and a consideration of methods of control occupied the attention not only of entomologists but of cane growers and field men generally. As none of the methods of chemical control or parasite introduction proposed by the entomologists proved to be economically feasible, or likely to produce results within a reasonable time, the field men were forced to adopt such obvious methods as hand picking of the grubs after the plow and of the adult beetles from young cane, expensive, essentially temporary and only partially effective as such methods admittedly were.

Today it is difficult to realize the seriousness of the white grub menace, for the grubs are no longer present. Hand collection of the grubs and beetles has been almost universally abandoned because it is no longer necessary, and is now so exceptionally used in rare instances only as to indicate how greatly the status of the white grub has changed. To be sure, cultivation practises have been improved, plowing is deeper, the land is better fitted for plant cane, and even the kind of cane itself is changed, being more vigorous varieties with stronger and more rapidly developing root systems, but these are only minor factors to account for the practical disappearance of the native white grubs generally from the cultivated fields of Puerto Rico.

The major factor in a changed environment for white grubs is the introduction and wide-spread dispersal of the giant toad, Bufo marinus L. Nearly a third of the food of this animal in cane fields consists of May beetles, the adults of the white grubs. If the toads were comparatively scarce, as are the native toads for instance, their influence might be negligible, but as a matter of fact they are at the present time very numerous, not only along the coast, but also far up into the hi!lier districts of the interior. On account of their individual size, their abundance, and their preference for May beetles as food, they have rapidly changed the status of white grubs in the cane fields of the south coast, and in the agricultural regions of the island generally, from that of a major pest to one of comparatively minor importance. No prediction can be ventured as to how long this condition will last: whether it is merely a temporary low for white grubs, or whether it may possibly be more or less permanent, 
a permanent adjustment to the new factor. When the oscillations of the balance of nature are upset by the introduction of a new major factor, usually the numbers of the host are so greatly reduced by the parasite or predator that the parasite or predator shortly must perish in large numbers on account of lack of food. In the case of such an omnivorous predator as the toad, however, not limited in its choice of food to any particular kind of insect, the prospect of many individuals starving to death on account of lack of food may be indefinitely postponed, even if May beetles become much scarcer than they are at present. A considerable number of other Scarabaeid beetles, of little or no direct economic importance, but almost the equivalent individually of the May beetles in size, are very abundant at times, and these constitute even now a seventh of the food of toads in cane fields, and may come to be a more important factor if the number of May beetles shows a decrease below its present previously unprecedented low.

Combining all the Scarabaeid beetle items in the toad's food (amounting to nearly half of all food eaten) and adding to this an additional quarter consisting of millipedes, one can readily see how little is to be expected from the toad in affecting other insects, for the present at least, and so long as a sufficient supply of May beetles and millipedes is available. Eventually the changa may be much more generally eaten, but it was found to be only one-fortieth of the food in 1930-31 (2). Is it surprising that the changa continues to be a major pest, and that white grubs have almost disappeared?

At times, and locally, even exceeding white grubs in numbers and in the damage it causes to cane is the weevil root-borer grub, Diaprepes abbreviatus $\mathrm{L}$., the adult of which is an exclusively aerial, leaf-feeding, short-beaked weevil. The adult beetles rarely feed on cane leaves, but are a serious pest of citrus trees, especially of young trees which have just been set out in the grove, and they also feed on the tender leaves of numerous other trees of little or no economic value. So far as can be judged, the numbers of this pest now average little less than at any time in the past. Altho the exclusively aeriai habits of the adults might appear to render them largely immune from being eaten by toads, the weevils in fact form the third largest single item in its food, an eighth of the total. Eventually this may be considerably increased if other large insects, such as the Scarabaeid beetles, become less numerous, and seems not only possible but decidedly probable. One other important factor tending to limit the number of Diaprepes is an egg parasite, Tetrastichus haitiensis Gahan. Not until 1929 was this common insect discovered in Puerto 
Rico, but its so recent discovery can hardly mean that it was not previously present. The parasite is so common that it ordinarily destroys from 50 to 95 per cent of all egg-clusters laid between the leaves of citrus or wild fig, but it can not penetrate to the eggs when they are laid between the split tips of cane leaves, and these only were collected and examined by the earlier investigators. Thus the egg parasite is not a new controlling factor, like the introduced toad. and is static, not likely to greatly increase in importance in the near future.

If any considerable decrease in the number of Diaprepes has already occurred (altho at present imperceptible to entomologists or farmers generally), or does occur within the next few years, it presumably will not be due to egg-parasites, but to a scarcity of other food forcing the imported toad to eatch and eat larger numbers of these leaf weevils.

\section{BIBLIOGRAPHY}

1. Wolcott, G. N. and Seín, Jr., Francisco. "A Year's Experience with the Cottony Cushion Scale in Puerto Rico." Jour. Dept. Agr. P. R., 17:199-221, pl. 4, ref. 11. San Juan, July (actually September), 1933.

2. Dexter, Raquel R. "The Food Habits of the Imported Toad Bufo Marinus in the Sugar Cane Sections of Porto Rico." Bulletin No. 74, Fourth Congress, International Society of Sugar Cane Technologists, p. 6, tab. 11, ref. 6. San Juan, March 1st to 16th, 1932. 